AperTO - Archivio Istituzionale Open Access dell'Università di Torino

\title{
Enabling technologies for the rapid dechlorination of polychloroarenes and PCBs
}

\section{This is the author's manuscript}

Original Citation:

Availability:

This version is available http://hdl.handle.net/2318/143040

since

Terms of use:

Open Access

Anyone can freely access the full text of works made available as "Open Access". Works made available under a Creative Commons license can be used according to the terms and conditions of said license. Use of all other works requires consent of the right holder (author or publisher) if not exempted from copyright protection by the applicable law. 


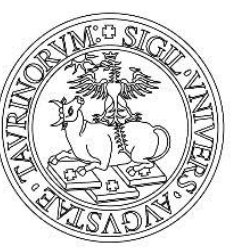

\section{UNIVERSITÀ DEGLI STUDI DI TORINO}

3 This Accepted Author Manuscript (AAM) is copyrighted and published by Elsevier. It is 4 posted here by agreement between Elsevier and the University of Turin. Changes 5 resulting from the publishing process - such as editing, corrections, structural formatting, 6 and other quality control mechanisms - may not be reflected in this version of the text. 7 The definitive version of the text was subsequently published in [Chemosphere, Vol.9, 8 Issue, 2013, DOI: 10.1016/j.chemosphere.2013.03.030].

10 You may download, copy and otherwise use the AAM for non-commercial purposes 11 provided that your license is limited by the following restrictions:

(1) You may use this AAM for non-commercial purposes only under the terms of the CC-

15 (2) The integrity of the work and identification of the author, copyright owner, and 16 publisher must be preserved in any copy.

17 (3) You must attribute this AAM in the following format: Creative Commons BY-NC-

18 ND license (http://creativecommons.org/licenses/by-nc-nd/4.0/deed.en), [DOI:

19 10.1016/j.chemosphere.2013.03.030] 


\section{Enabling Technologies for the Rapid Dechlorination of Polychloroarenes and PCBs}

Giancarlo Cravotto, ${ }^{* \dagger}$ Davide Garella, ${ }^{\dagger}$ Lara Beltramo, ${ }^{\dagger}$ Diego Carnaroglio, + Stefano Mantegna, ${ }^{+}$and Carlo Maria Roggero. ${ }^{\ddagger}$

+ Dipartimento di Scienza e Tecnologia del Farmaco, Università di Torino, Via P. Giuria 9, Torino 10125, Italy.

\# Sea Marconi Technologies, Via Ungheria 20, 10093 Collegno (TO), Italy.

*E-mail: giancarlo.cravotto@unito.it; Fax: +39 011 6707687; Tel: +390116707684

\section{Abstract}

Dielectric heating and acoustic cavitation (ultrasound or highperformance disperser) may all dramatically enhance conversion rates and yields in heterogeneous metal-assisted organic reactions even when low reagent excesses are used. These so called "enabling technologies" bring with them process intensification, safer protocols, cost reduction and energy savings. We herein describe a series of rapid polychlorinated aromatic and PCBs dechlorinations (15 min) carried out in a moderate excess of metallic sodium and using non-conventional techniques. We compared the results with those obtained for reactions carried out under conventional heating and with those performed with less reactive metals such as magnesium and zinc. In this comparison, high-intensity ultrasound stands out as the technique of choice.

KEYWORDS. Polychloroarenes, PCBs, Dechlorination, Ultrasound, Microwaves, High-performance disperser. 


\section{Introduction}

60 Reductive dechlorination has become one of the most attractive

61 topics in chemistry since the Stockholm Convention on Persistent

62 Organic Pollutants (POPs) imposed the elimination of

63 polychlorinated biphenyls (PCBs) use by 2025 and their disposal via

64 environmentally sound waste management by 2028. Besides

65 incineration or high temperature pyrolysis, which are powerful but

66 controversial elimination methods, there are several non-

67 combustion alternatives to be considered. These are reported in

68 Table 1. Of the several dechlorination methods available, the metal

69 based process has been singled out as the most cost effective and

70 efficient because no toxic by-products (i.e. biphenyl,

71 phenylcyclohexadiene, and phenylcyclohexene) are formed.

72 Nevertheless, safety concerns have been voiced over the huge

73 metal excess that is usually required. Alkaline-earth metals (Ca,

$74 \mathrm{Mg}$ ) and transition metals ( $\mathrm{Ni}, \mathrm{Pd}, \mathrm{Fe}, \mathrm{Ti}$ and $\mathrm{Zn}$ ) (Mitoma et al.,

75 2004; Upendra and Suresh, 2008; Azzena et al., 2010; Liu et al.,

76 2009; Zhang et al., 2011; Zhang, 2003; Fuku et al., 2010; Feng

77 and Lim, 2005) have been investigated as alternatives to the

78 alkaline metals (mainly $\mathrm{Na}$ ) that are normally used. The reaction

79 times of PCB dechlorination are in the region of several hours or

80 even days. The use of alternative energy sources, such as

81 microwaves (MW) (Kappe, 2004), ultrasound (US) (Cravotto and

82 Cintas, 2006) or mechanochemistry (Nasir and Varma, 2012; Stolle 
83 et al., 2011) has been proven to strongly accelerate the reductive

84 process and limit gaseous emissions (Tajik et al., 2012; Liu et al.,

85 2011; Zhang and Hua, 2000; Sáez, 2011).

86

87

Table 1. Non-combustion technologies for PCBs degradation.

88

\begin{tabular}{|c|c|c|}
\hline METHOD & CHARACTERISTICS & Ref. \\
\hline $\begin{array}{l}\text { Reduction with } \\
\text { alkali-metals }\end{array}$ & $\begin{array}{l}\text { - } \text { Metal stability is a crucial } \\
\text { factor (i.e. Ca vs } \mathrm{Na} \text { ) } \\
\text { - } \text { Mild conditions (r.t., } \mathrm{N}_{2} \\
\text { atmosphere) } \\
\text { - Improved by catalysts (i.e. } \\
\text { Pd/C, } \mathrm{TiCl}_{4}, \mathrm{CoCl}_{2}, \mathrm{Ni}(\mathrm{OAc})_{2} \text { ) }\end{array}$ & $\begin{array}{l}\text { Chiu, et al., 2012; } \\
\text { Noma, et al., } 2003 .\end{array}$ \\
\hline $\begin{array}{l}\text { Base-catalyzed } \\
\text { decomposition }\end{array}$ & $\begin{array}{l}\text { - Cost-effective and safe } \\
\text { dechlorination occurs with } \\
\text { alkali hydroxides }\end{array}$ & $\begin{array}{l}\text { Takada, et al., 1997; } \\
\text { Sun, et al., 2007; } \\
\text { Ye, et al., 2011. }\end{array}$ \\
\hline $\begin{array}{l}\text { Catalytic hydro- } \\
\text { dechlorination }\end{array}$ & $\begin{array}{l}\text { - Heterogeneous catalysts (i.e. } \\
\mathrm{Fe}, \mathrm{Ni} \text {, or } \mathrm{Pd} \text { ) and } \mathrm{H}_{2} \text { pressure } \\
\text { - Aqueous or organic solvents } \\
\text { - Generation of biphenyls, } \mathrm{HCl}\end{array}$ & $\begin{array}{c}\text { Schüth and } \\
\text { Reinhard, } 1998 .\end{array}$ \\
\hline $\begin{array}{l}\text { Photochemical - } \\
\text { electrochemical } \\
\text { processes }\end{array}$ & $\begin{array}{l}\text { - } \text { Closed systems, mild and } \\
\text { eco-friendly conditions } \\
\text { - Safe additives (i.e. 2- } \\
\text { propanol) }\end{array}$ & $\begin{array}{l}\text { Hawarl, et al., 1992; } \\
\text { Noma, et al., 2002; } \\
\text { Ghosh, et al., 2012. }\end{array}$ \\
\hline Plasma arc & $\begin{array}{l}\text { - High efficiency } \\
\text { - Environmentally friendly } \\
\text { - Generation of } \mathrm{H}_{2} \mathrm{O}_{2}, \mathrm{H}_{2}, \mathrm{O}_{2}, \mathrm{O}_{3} \\
\text { (also radicals) } \\
\text { - Shock waves and UV light } \\
\text { may occur simultaneously } \\
\text { - Mandatory energy control }\end{array}$ & Du, et al., 2005. \\
\hline $\begin{array}{l}\text { Microbial } \\
\text { reductive } \\
\text { transformation }\end{array}$ & $\begin{array}{l}\text { - Temperature, } \mathrm{pH} \text {, substrate } \\
\text { composition monitoring for } \\
\text { microorganisms growth } \\
\text { - Slow process }\end{array}$ & $\begin{array}{l}\text { Borja, et al., 2005; } \\
\text { Field and Sierra- } \\
\text { Alvarez, } 2008 .\end{array}$ \\
\hline
\end{tabular}

89

90 The use of metal particles in a MW oven can result in arcing and

91 generate fire or explosion if a flammable solvent is present. It is,

92 however, possible to perform organic reactions using well-dispersed 
93 fine metal particles in a high-boiling-point polar solvent. Whittaker

94 and Mingos described all the safety operations needed to minimize

95 the risk of arcing which include moderating the power rating, using

96 low metal loads and ensuring efficient stirring (Whittaker and

97 Mingos, 2000). Kappe showed, for the first time, how the electric

98 field strength could influence the outcome of a chemical reaction. In

99 low field density conditions, the metal undergoes a cleaning effect

100 and becomes more reactive, whereas under a more intense

101 electrostatic discharge the high temperature reached generates a

102 carbonaceous material that covers the metal, thus reducing its

103 effect (Gutmann et al., 2011). Besides the close control of electric

104 field strength, another method that can influence this type of

105 reaction is the use of an inert atmosphere ( $\mathrm{N}_{2}$ or $\mathrm{Ar}_{2}$ pressure). This

106 provides a totally safe environment in which to carry out the

107 procedure as it avoids the risk of combustion and explosion in all

108 MW reactions that use metals in a pivotal role (Cintas et al., 2012).

109 US has found several applications in metal-assisted reactions

110 (Cintas et al., 2011) and in heterogeneous conditions (Cravotto et

111 al., 2003; Palmisano et al. 2011).

112 High-intensity US induces strong acoustic cavitation and streaming

113 which enable efficient mixing, metal surface activation and particle

114 dispersion to occur (Cravotto and Cintas, 2006). In the present

115 study we intend to show how US, MW and high-performance 
116 disperser favor the rapid metal-assisted dechlorination of

117 polychloroarenes and PCBs.

118

119 2. Materials and methods

120 2.1. Materials

121 All the chemicals were used as received. 1,3,5-trichlorobenzene

$122(<99 \%)$ and hexachlorobenzene were purchased from Fluka

123 Chemika, 2,4-dichlorophenol (99\%) and a sodium dispersion 30

$124 \mathrm{wt} \%$ in toluene $(<0.1 \mathrm{~mm}$ particles size $)$ were purchased from Acros

125 Organics. Sodium cubes (99.95\%), magnesium chips (98\%) and Zn

126 powder were purchased from Sigma-Aldrich. PCBs oil: (Askarel by

127 Monsanto) a mixture of Aroclor $126070 \%$ and trichlorobenzene

$12830 \%$. The US probe system $(21.1 \mathrm{kHz}$, max power $250 \mathrm{~W}, \varnothing=2.92$

$129 \mathrm{~cm}$ ) with a titanium horn is commercially available from

130 Danacamerini s.a.s. (Turin, Italy). MW-assisted reactions were

131 carried out under pressure in a SynthWAVE by Milestone (Bergamo,

132 Italy). An Ultra Turrax ${ }^{\circledR}$ T 25 Basic by IKA was used as the high-

133 performance disperser.

134 2.2. Gaschromatography Analysis

135 a) Polychloroarenes; gaschromatography-mass spectrometry (GC-

136 MS) analyses were performed in a Agilent 6890 gaschromatograph

137 (Agilent Technologies - USA) fitted with a Agilent Network 5973

138 mass detector using a $30 \mathrm{~m}$ long capillary column, an i.d. of 0.25

$139 \mathrm{~mm}$ and a film thickness of $0.25 \mu \mathrm{m}$. 
140 GC conditions were; injection split 1:20, injector temperature

$141250^{\circ} \mathrm{C}$, detector temperature $280^{\circ} \mathrm{C}$. Gas carrier: helium (1.2

$142 \mathrm{~mL} / \mathrm{min})$, temperature program; from $70^{\circ} \mathrm{C}(2 \mathrm{~min})$ to $300^{\circ} \mathrm{C}$ at $1435^{\circ} \mathrm{C} / \mathrm{min}$.

144 b) PCBs; Gaschromatography-electron capture detector (GC-ECD) 145 analyses were performed in a Agilent 6890 gaschromatograph 146 (Agilent Technologies - USA) fitted with an ECD, using a $50 \mathrm{~m}$ long $1475 \%$ phenylpolysiloxane capillary column, i.d of $0.20 \mathrm{~mm}$ and film

148 thickness $0.33 \mu \mathrm{m}$. Gas carrier; helium ( $1 \mathrm{~mL} / \mathrm{min})$, make-up gas

149 for ECD; argon-methane (5\%). ECD temp. $340^{\circ} \mathrm{C}$. Splitless injection

$1501 \mu \mathrm{L}$. Temperature program: from $120^{\circ} \mathrm{C}(1 \mathrm{~min})$, then $50^{\circ} \mathrm{C} / \mathrm{min}$ up

151 to $200^{\circ} \mathrm{C}(1 \mathrm{~min}) ; 5 \mathrm{C} \% / \mathrm{min}$ up to a $270^{\circ} \mathrm{C} ; 20 \mathrm{C}^{\circ} / \mathrm{min}$ up to $315^{\circ} \mathrm{C}$.

152 2.3. MW under pressure

153 Aryl halide $(0.1 \mathrm{mmol}, 1 \mathrm{eq})$, metallic reagent (15 eq of metal for 154 each $\mathrm{Cl}$ atom) and toluene $(10 \mathrm{~mL})$ were placed in the reaction 155 vessel. The mixture was irradiated with MW (average power $300 \mathrm{~W}$ ) 156 at $130^{\circ} \mathrm{C}$ for the optimized time of 15 min under $\mathrm{N}_{2}$ pressure (5 157 bar). The solution was filtered on a Celite ${ }^{\circledR}$ pad, soaked in ethanol 158 to remove any un-reacted sodium and analyzed by GC-MS.

159 2.4. US and the high-performance disperser

160 Aryl halide $(0.1 \mathrm{mmol}, 1 \mathrm{eq})$, the metallic reagent (15 eq of metal 161 for each $\mathrm{Cl}$ atom) and hexadecane $(10 \mathrm{~mL})$ were placed in a three162 necked-round-bottomed flask. The mixture, pre-heated in an oil 163 bath at $130^{\circ} \mathrm{C}$ until the sodium melted, was then sonicated with an 
164 immersion horn $(21.1 \mathrm{kHz}, 60 \mathrm{~W})$ for $15 \mathrm{~min}$. In an alternative

165 procedure, a high-performance disperser probe was inserted into 166 the flask and switched on/off intermittently every minute for a total

167 time of 30 min ( 15 min high speed mixing and 15 min pause) to 168 avoid super-heating and damage to the Ultra Turrax ${ }^{\circledR}$. The solution 169 was filtered on a Celite ${ }^{\circledR}$ pad, soaked in ethanol to remove any un-

170 reacted sodium and analyzed by GC-MS.

171

\section{3. Results and discussion}

173 In this paper, enabling technologies have been applied to the

174 dechlorination process with the aim of designing a safe, fast and

175 efficient protocol in the presence of a low alkali-metal excess ( $\leq 15$

176 eq.). Four different techniques have been applied; MW, US, high-

177 performance disperser (Ultra Turrax $^{\circledR}$ ) and simple conductive

178 heating in an oil bath (OB) was used as a conventional method

179 reference. The three main parameters that affect the dechlorination

180 rate were; temperature, mixing efficiency and metal/chlorine atom

181 ratio (scheme 1 ).

182

183 Scheme 1. Reductive dechlorination with non-conventional 184 techniques.

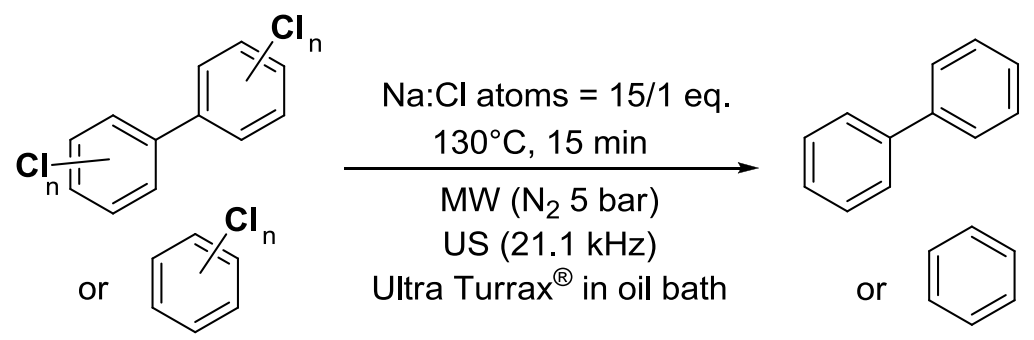


186 In this work, dechlorination reactions were carried out by

187 suspending the reducing metal (mainly $\mathrm{Na}, 15$ eq. for each $\mathrm{Cl}$ atom)

188 in toluene or a hexadecane solution containing a polychloroarene.

189 The first set of experiments was conducted with trichlorobenzene,

190 2,4-dichlorophenol and hexachlorobenzene.

191 MW-assisted dechlorination reactions were performed in a closed

192 MW reactor (SynthWAVE - Milestone) under nitrogen pressure (5

193 bar) thus avoiding any possible risk of fire and explosion. The high

194 power density ( $1.5 \mathrm{~kW}$ per $1.5 \mathrm{I})$ and the efficient cooling system

195 enabled fast volumetric heating and rapid cooling with very sharp

196 temperature ramps.

197 Table 2 reports the results achieved for MW-assisted reactions 198 according to the varying conditions and sodium source (sodium 199 cubes or a dispersion $30 \mathrm{wt} \%$ in toluene). In the light of the results 200 obtained in a few preliminary experiments with 10 eq. (entry 5), we

201 decided to proceed with a metal excess of 15 eq. for each $\mathrm{Cl}$ atom. 202 Although the reactions proceed well in 30 minutes at $150^{\circ} \mathrm{C}$ (entries 2031,10 and 17), we also investigated milder conditions at the same 204 reaction time. Complete dechlorination was also achieved (entries 2, 20511 and 18 ) when the reaction was carried out at $130^{\circ} \mathrm{C}$, whilst no 206 reaction occurred within the 30 min period at temperatures below 207 the metal melting point (entries 9, 16 and 23). However, the 208 sodium dispersion showed much higher reactivity than the sodium 209 cubes when the temperature was close to the metal melting point 
210 because of its higher particle dispersion (entries 8,15 and 22 ). A

211 temperature of $130^{\circ} \mathrm{C}$ together with a sodium/chlorine atom ratio of

21215 eq. and an average reaction time of $15 \mathrm{~min}$ was the best

213 compromise in the case of MW-promoted reactions. Lower

214 dechlorination yields were detected working under reflux in an OB

215 (entry 3,12 and 19).

216

217 Table 2. Residual polychloroarenes after MW-promoted 218 dechlorination with $\mathrm{Na}$ (15 eq.) in toluene (5 bar $\mathrm{N}_{2}$ pressure).

219

\begin{tabular}{|c|c|c|c|c|c|}
\hline Entry & Substrate $^{\#}$ & $\begin{array}{l}\text { Time } \\
(\mathrm{min})\end{array}$ & $\begin{array}{c}\text { Temperature } \\
\left({ }^{\circ} \mathrm{C}\right)\end{array}$ & $\begin{array}{c}\text { Na cubes } \\
\text { (residual \%) }\end{array}$ & $\begin{array}{l}\text { Na dispersion } \\
\text { (residual \%) }\end{array}$ \\
\hline 1 & & 30 & 150 & 0 & 0 \\
\hline 2 & & 30 & 130 & 0 & 0 \\
\hline 3 & & 30 & OB reflux & 67 & 60 \\
\hline 5 & & 30 & 130 & $14^{*}$ & $10^{*}$ \\
\hline 6 & & 15 & 130 & 0 & 0 \\
\hline 7 & & 7 & 130 & 55 & 54 \\
\hline 8 & & 30 & 100 & 80 & 0 \\
\hline 9 & & 30 & 80 & 100 & 100 \\
\hline 10 & & 30 & 150 & 0 & 0 \\
\hline 11 & $\mathrm{OH}$ & 30 & 130 & 0 & 0 \\
\hline 12 & & 30 & OB reflux & 52 & 44 \\
\hline 13 & & 15 & 130 & 0 & 0 \\
\hline 14 & & 7 & 130 & 13 & 17 \\
\hline 15 & CI & 30 & 100 & 33 & 0 \\
\hline 16 & & 30 & 80 & 100 & 100 \\
\hline 17 & & 30 & 150 & 0 & 0 \\
\hline 18 & & 30 & 130 & 0 & 0 \\
\hline 19 & & 30 & OB reflux & 100 & 96 \\
\hline 20 & & 15 & 130 & 0 & 0 \\
\hline 21 & & 7 & 130 & 85 & 56 \\
\hline 22 & & 30 & 100 & 100 & 78 \\
\hline 23 & & 30 & 80 & 100 & 100 \\
\hline
\end{tabular}

$220 \quad$ " In the cases of incomplete conversion, GC-MS analysis did not detect partially

221 dechlorinated compounds; results are the mean of at least 2-3 trials

$222 *$ Na 10 eq. 
224 The optimization of the MW-assisted procedure caused a decrease

225 in reaction time to 15 (entries 6, 13 and 20) and 7 min (entries 7,

22614 and 21), where the former is the preferred choice. This study

227 has provided us with the following order of reactivity; 2,4-

228 dichlorophenol >> 1,3,5-trichlorobenzene > hexachlorobenzene.

229 The last in the list was the most refractory towards dechlorination.

230 The MW-assisted procedure was employed in experiments carried

231 out with US (average power of $80 \mathrm{~W}$ ) and with high-performance

232 dispersers (Ultra Turrax ${ }^{\circledR}$ at $10,000 \mathrm{rpm}$ ). Both methods generate

233 cavitation phenomena and cause the reactive metal to be very finely

234 dispersed. Moreover they played a pivotal role in the set up of this

235 protocol ensuring the process was strongly accelerated. Since the

236 experiments were carried out at atmospheric pressure and at

$237130^{\circ} \mathrm{C}$, toluene was replaced with hexadecane. A constant

238 hexadecane solution reaction temperature was guaranteed by a

239 thermostatted bath $\left(130^{\circ} \mathrm{C}\right)$. At this temperature, the metallic

240 sodium (cubes) melted $\left(97.7^{\circ} \mathrm{C}\right)$ and therefore easily dispersed into

241 the medium, however, particle size was a crucial point for the other

242 metals (zinc and magnesium). Melting proceeded even more quickly

243 when a commercially available sodium dispersion was used (30 wt\%

244 in toluene, $<0.1 \mathrm{~mm}$ particles size). Table 3 shows the results

245 achieved with the sodium dispersion, zinc and magnesium. The

246 sodium dispersion gave excellent yields, confirming the results 
247 obtained with the MW protocol. The yields were significantly lower in

248 the presence of magnesium and zinc as they act in the solid phase.

250 Table 3. Residual polychloroarenes after treatment with US or a 251 high-performance disperser with various metals (15 eq.) in 252 hexadecane for $15 \mathrm{~min}$ at $130^{\circ} \mathrm{C}$.

253

\begin{tabular}{cccccc}
\hline \multirow{2}{*}{ Entry } & \multirow{2}{*}{ Method $^{*}$} & \multirow{2}{*}{ Substrate } & \multicolumn{3}{c}{ Residual \% } \\
\cline { 4 - 6 } & & Na dispersion & Mg & Zn \\
\hline 24 & \multirow{2}{*}{ US } & 2,4-dichlorobenzene & 0 & 91 & 92 \\
25 & hexachlorophenol & 0 & 83 & 76 \\
26 & & trichlorobenzene & 0 & 100 & 100 \\
\hline 27 & \multirow{2}{*}{$*$ Ultra } & 2,4-dichlorophenol & 4 & 92 & 95 \\
28 & Turrax $^{\circledR}$ & hexachlorobenzene & 10 & 90 & 88 \\
29 & & & 0 & 100 & 100 \\
\hline
\end{tabular}

$254 \quad$ "Results are the mean of $2-3$ trials

$255{ }^{*}$ Alternatively on/off $1 \mathrm{~min}$ (15 min high speed mixing and 15 min pause).

256

257 The optimized procedures; MW carried out in a pressurized reactor,

258 high-intensity US with an immersion horn and the high-performance

259 disperser (Ultra Turrax ${ }^{\circledR}$ at $10,000 \mathrm{rpm}$ ) were also tested in the

260 dechlorination of PCBs. A mineral oil containing $271 \mathrm{ppm}$ of PCBs

261 was used to this aim and was treated with a sodium dispersion at

$262130^{\circ} \mathrm{C}$ for $15 \mathrm{~min}$ with all techniques. After a few preliminary

263 experiments we defined a sodium excess value of 40 mole eq. as

264 being optimal. Table 4 summarizes the results achieved; 7 ppm with

$265 \mathrm{MW},<2 \mathrm{ppm}$ with US, $28 \mathrm{ppm}$ with Ultra Turrax ${ }^{\circledR}$, whilst the

266 reference reaction in an oil bath gave a $120 \mathrm{ppm}$ residue. All the

267 reactions were monitored via GC-ECD. 
269 Table 4. Residual PCBs in mineral oil (271 ppm) under OB, Ultra 270 Turrax $^{\circledR}$, MW and US.

\begin{tabular}{ccccc}
\hline Entry & Method & $\begin{array}{c}\text { Time } \\
(\mathbf{m i n})\end{array}$ & $\begin{array}{c}\text { PCBs residual } \\
(\mathbf{p p m})\end{array}$ & $\begin{array}{c}\text { PCBs residual } \\
\text { ( } \mathbf{p p m}) \\
\text { Na (15 mole eq) }\end{array}$ \\
\hline 30 & Noil bath & 60 & 270 & 120 \\
31 & $*$ Ultra Turrax ${ }^{\circledR}$ & 15 & 79 & 28 \\
32 & MW & 15 & 56 & 7 \\
33 & US & 15 & 48 & $<2$ \\
\hline
\end{tabular}

271

*alternatively on/off 1 min (15 min high speed mixing and 15 min pause).

272

273

274

\section{Conclusion}

275 In conclusion, we have herein reported a dechlorination protocol

276 performed under non-conventional techniques that enables a

277 moderate excess of metallic sodium to be used rather than the

278 much higher excesses that are currently commonplace. On the basis

279 of the three main parameters studied, temperature, metal/chlorine 280 ratio and physical activation, we can conclude that the crucial issues 281 in the effectiveness of the procedure are the use of melted metal, a 282 reasonable sodium excess and efficient physical metal 283 activation/dispersion. Rapid reactions in low metal excesses (15 284 mole eq and 40 eq. for PCBs) are possible thanks to the enabling 285 technologies we have outlined above and would be impossible under 286 conventional heating.

288 Acknowledgement

289 Financial support from MAPSYN (grant 309376 - NMP.2012.3.0-1)

290 "Highly efficient syntheses using alternative energy forms" is 291 gratefully acknowledged. 


\section{References}

293 Mitoma, Y., Uda, T., Egashira, N., 2004. Approach to highly efficient 294 dechlorination of PCDDs, PCDFs, and coplanar PCBs using metallic 295 calcium in ethanol under atmospheric pressure at room 296 temperature. Environ. Sci. Technol. 38, 1216-1220.

297 Upendra, D., Suresh, S., 2008. Effects of solvent, pH, salts and 298 resin fatty acids on the dechlorination of pentachlorophenol using 299 magnesium-silver and magnesium-palladium bimetallic systems. 300 J. Hazard. Mater. 156, 308-316.

301 Azzena, U., Dettori, G., Mocci, S., Pisano, L., Cerioni, G., Mocci, F., 302 2010. Active-sodium-promoted reductive cleavage of halogenated 303 benzoic acids. Tetrahedron 66, 9171-9174.

304 Liu, G.-B., Masashi, T., Thiemann, T., 2009. A facile method for the 305 dechlorination of mono- and dichlorobiphenyls using Raney Ni-Al 306 alloy in dilute aqueous solutions of alkali hydroxides or alkali 307 metal carbonates. Tetrahedron 65, 2497-2505.

308 Zhang, C., Li, X., Sun, H., 2011. Palladium-catalyzed 309 hydrodechlorination of aryL chlorides and its mechanism. Inorg. 310 Chim. Acta 365, 133-136.

311 Zhang, W.-X., 2003. Nanoscale iron particles for environmental

312 remediation: An overview. J. Nanopart. Res. 5, 323-332.

313 Fuku, K., Hashimoto, K., Kominami, H., 2010. Photocatalytic

314 reductive dechlorination of chlorobenzene to benzene in 2315 propanol suspension of metal-loaded titanium(IV) oxide 
316 nanocrystals in the presence of dissolved sodium hydroxide.

317 Chem. Commun. 46, 5118-5120.

318 Feng, J., Lim, T.T., 2005. Pathways and kinetics of carbon 319 tetrachloride and chloroform reductions by nano-scale $\mathrm{Fe}$ and $320 \mathrm{Fe} / \mathrm{Ni}$ particles: comparison with commercial micro-scale Fe and 321 Zn. Chemosphere 59, 1267-1277.

322 Kappe, C.O., 2004. Controlled microwave heating in modern organic 323 synthesis. Angew. Chem. Int. Ed. 43, 6250-6284.

324 Cravotto, G., Cintas, P., 2006. Power ultrasound in organic 325 synthesis: moving cavitational chemistry from academia to 326 innovative and large-scale applications. Chem. Soc. Rev. 35, 180$327 \quad 196$.

328 Nasir Baig, R.B., Rajender Varma, S., 2012. Alternative energy 329 input: mechanochemical, microwave and ultrasound-assisted 330 organic synthesis. Chem. Soc. Rev. 41, 1559-1584.

331 Stolle, A., Szuppa, T., Leonhardt, S.E.S., Ondruschka, B., 2011. Ball 332 milling in organic synthesis: solutions and challenges. Chem. Soc. 333 Rev. 40, 2317-2329.

334 Tajik, R., Mohabadi, H.A., Khavanin, A., Joneidi, A., Eshreti, B., 335 Solimanian, A., 2012. Decomposition of PCBs(transformer oil) by 336 microwave radiation in presence of solvent and $\mathrm{H}_{2} \mathrm{O}_{2} / \mathrm{TiO}_{2}$ agents. 337 Adv. Environ. Biol. 6 (8), 2218-2225.

338 Liu, X., Zhao, W., Sun, K., Zhang, G., Zhao, Y., 2011. 339 Dechlorination of PCBs in the simulative transformer oil by 
340 microwave-hydrothermal reaction with zero-valent iron involved.

$341 \quad$ Chemosphere $82(5), 773-777$.

342 Zhang, G., Hua, I., 2000. Cavitation chemistry of polychlorinated

343 biphenyls: Decomposition mechanisms and rates. Environ. Sci.

344 Technol. 34 (8), 1529-1534.

345 Sáez, V. , Esclapez, M.D. , Bonete, P., 2011. Sonochemical

346 degradation of perchloroethylene: The influence of ultrasonic 347 variables, and the identification of products. Ultrason. Sonochem. $348 \quad 18,104-113$.

349 Wu, B.-Z., Chen, H.-Y., Wang, S.J., Wai, M.C., Liao, W., Chiu, K., 350 2012. Reductive dechlorination for remediation of polychlorinated 351 biphenyls. Chemosphere 88, 757-768.

352 Noma, Y., Mitsuhara, Y., Matsuyama, K., Sakai, S., 2007. Pathways 353 and products of the degradation of PCBs by the sodium dispersion 354 method. Chemosphere 68, 861-869.

355 Takada, M., Uchida, R., Taniguchi, S., Hosomi, M., 1997. Chemical 356 dechlorination of PCBs by the base catalyzed decomposition 357 process, Organohalogen. Compd. 31, 435-440.

358 Sun, Z., Takahashi, F., Odaka, Y., Fukushi, K., Oshima, Y., 359 Yamamoto, K., 2007. Effects of potassium alkalis and sodium 360 alkalis on the dechlorination of $o$-chlorophenol in supercritical 361 water. Chemosphere 66, 151-157. 
362 Ye, X., Jianguo, J., Yong, Y., Guolong, G., 2011. Base-catalyzed

363 destruction of hexachlorobenzene with zero-valent iron. Chem. 364 Eng. J. 173, 415-421.

365 Schüth, C., Reinhard, M., 1998. Hydrodechlorination and 366 hydrogenation of aromatic compounds over palladium on alumina 367 in hydrogen-saturated water. App. Catal., B 18, 215-221.

368 Hawarl, J., Demeter, A., Samson, R., 1992. Sensitized photolysis of 369 polychlorobiphenyls in alkaline 2-Propanol: Dechlorination of 370 Aroclor 1254 in soil samples by solar radiation. Environ. Sci. 371 Technol. 26, 2022-2027.

372 Noma, Y., Muramatu, T., Nishizawa, K., Ohno, M., Sakai, S., 2002.

373 Dechlorination pathways of PCBs by photochemical reaction and 374 catalytic hydrodechlorination. Organohalogen. Compd. 56, 413375416.

376 Ghosh, J.P., Achari, G., Langford, C.H., 2012. Reductive 377 dechlorination of PCBs using photocatalyzed UV light. CLEAN 40, $378 \quad(5), 455-460$.

379 Du, C.M., Yan, J.H., Cheron, B.G., 2005. Degradation of 4380 chlorophenol using a gas-liquid gliding arc discharge plasma 381 reactor. Plasma Chem. Plasma Process. 27, 635-646.

382 Borja, J., Taleon, D.M., Auresenia, J., Gallardo, S., 2005. 383 Polychlorinated biphenyls and their biodegradation. Process 384 Biochem. 40, 1999-2013. 
385 Field, J.A., Sierra-Alvarez, R., 2008. Microbial transformation and 386 degradation of polychlorinated biphenyls. Environ. Pollut. 155, 1$387 \quad 12$.

388 Whittaker, A.G., Mingos, D.M.P., 2000. Arcing and other microwave 389 characteristics of metal powders in liquid systems. J. Chem. Soc. 390 Dalton Trans., 1521-1526.

391 Gutmann, B., Schwan, A.M., Reichart, B., Gspan, C., Hofer, F., 392 Kappe, C.O., 2011. Activation and deactivation of a chemical 393 transformation by an electromagnetic field: evidence for specific 394 microwave effects in the formation of grignard reagents. Angew. 395 Chem. Int. Ed. 50, 7636-7640.

396 Cintas, P., Carnaroglio, D., Rinaldi, L., Cravotto, G., 2012. 397 Complementary and synergic effects of microwaves and 398 ultrasound in metal-assisted synthesis. Chemistry Today 30, 3339935.

400 Cintas, P., Palmisano, G., Cravotto, G., 2011. Power ultrasound in 401 metal-assisted synthesis: from classical Barbier-like reactions to 402 Click Chemistry. Ultrason. Sonochem. 18, 836-841.

403 Cravotto, G., Nano, G.M., Palmisano, G., Tagliapietra, S., Demetri, 404 A., Penoni, A., 2003. The aldol reaction under high intensity 405 ultrasounds: a novel approach to an old reaction. Eur. J. Org. $406 \quad$ Chem. 22, 4438-4444.

407 Palmisano, G., Tibiletti, F., Penoni, A., Colombo, F., Tollari, S., 408 Garella, D., Tagliapietra, S., Cravotto, G., 2011. Ultrasound- 
409

enhanced one-pot

synthesis of

3-(Het)arylmethyl-4-

410 hydroxycoumarins in water. Ultrason. Sonochem. 18, 652-660. 